Review

\title{
Caustic esophageal stricture from diagnosis untill cure
}

\author{
Sameh Abdelhay ${ }^{a}$, Mohamed Moussa ${ }^{a}$, Mohammed Elsherbeny ${ }^{a,}$ \\ ${ }^{a}$ Department of Pediatric Surgery, Faculty of Medicine, Ain Shams University, Cairo, Egypt.
}

\begin{abstract}
Background: The diagnosis of esophageal stricture after caustic ingestion is based on clinical symptoms of dysphagia, regurgitation and chocking that is evident initially in the acute stage. These symptoms may ameliorate by time or proceed to evident stricture due to fibrosis. This will need either dye esophagogram or Esophagoscopy which is better to be done not before the lapse of at least 6 weeks from injury. Esophageal dilatation using wire-guided dilators is the cornerstone of treatment. The frequency of dilatation is based on recurrence of dysphagia and in multiple strictures, repeated sessions with multi-level injection of steroids and graded dilatation is needed. Failure of dilatation or occurrence of complications may necessitate esophageal replacement and usually we prefer the transverse colon based on the left colic vessels in retrosternal position to treat the condition. We aimed to review the management of caustic esophageal strictures based on what is known and adding our experience in this aspect.

Methods: We reviewed the articles discussing management of caustic esophageal strictures in the last twenty years. We added our experience of more than forty years managing an average of thirty new cases every year. Results: Management of caustic esophageal strictures has changed in the last years. Advanced endoscopic techniques of dilatation reduced the need for esophageal replacement.

Conclusions: Caustic esophageal strictures could be managed successfully with advanced techniques of endoscopic dilatation.

Keywords: Caustic stricture; esophageal dilatation; esophagoscopy; esophageal replacement
\end{abstract}

\section{INTRODUCTION}

The ingestion of caustics usually occurs due to accidental swallowing, and the effect will depend on the type of caustic substance either acid or alkali and its concentration. High concentration either acid or alkali causes severe injury to the mouth, pharynx, and larynx with severe affection of the esophagus up to complete necrosis. More diluted forms of alkali will affect mainly the esophagus causing damage of the mucosa and muscle layer with subsequent stricture depending on the amount swallowed. Ingestion of acid will affect mainly

*Corresponding author: Dr. Mohammed Elsherbeny Mailing address: Department of Pediatric Surgery, Faculty of Medicine, Ain Shams University, Lotfy Elsayed St, Abbassyyah, Cairo, Egypt.

E-mail: mohamedsaid@med.asu.edu.eg

Received: 02 Apirl 2020 Accepted: 08 May 2020 the gastric outlet causing pyloric obstruction. Initially all patients will have variable degrees of dysphagia that may resolve if the injury is trivial, but it will persist if a stricture supervenes.

Action needed for management of the resultant dysphagia will be tailored depending on its degree; absolute dysphagia better to be managed by initial gastrostomy for maintaining the nutritional status of the patients. Dysphagia to solids and semisolids can be managed expectantly by nutritive oral fluid intake. Further management will depend on the management protocol for treating esophageal stricture by initial dye study to define the character of the stricture followed by a trial of dilatation.

\section{CLINICAL MANIFESTATIONS AND DIAG- NOSIS}

Stricture formation is manifested by variable degrees of dysphagia, ranging from dysphagia to solids or semisolids to absolute dysphagia with drooling of saliva and 
repeated chest infections from aspiration secondary to spill over or tracheo-esophageal fistula (Figure. 1 and 2). Manifestations of respiratory tract affection may present with stridor, hoarseness of voice, dyspnea or tachypnea ${ }^{[1,2]}$.

After the lapse of at least 3-4 weeks, dye study should be done carefully using water soluble non-irritant dye for the fear of aspiration and subsequent pneumonitis due to spill over or the presence of fistula. The study should be done under screen and the dye is given orally or injected slowly through a naso-esophageal tube with suction device ready beside the patient. It will provide a basic image before doing an intervention. The study will demonstrate the site, the number, the length and the diameter of the stricture and will show associated gastro esophageal reflux or pull up of the stomach by esophageal fibrosis causing hiatus hernia. Once the diagnosis of stricture is evident, the patient is scheduled for upper endoscopy after the lapse of at least 6 weeks from the initial injury. The data obtained from the contrast study should be correlated with that found on endoscopy ${ }^{[3,4]}$. Some studies recommended doing endoscopy in the first 12-48 hours after the ingestion. Although it has the advantage of assessing the degree of affection and hence

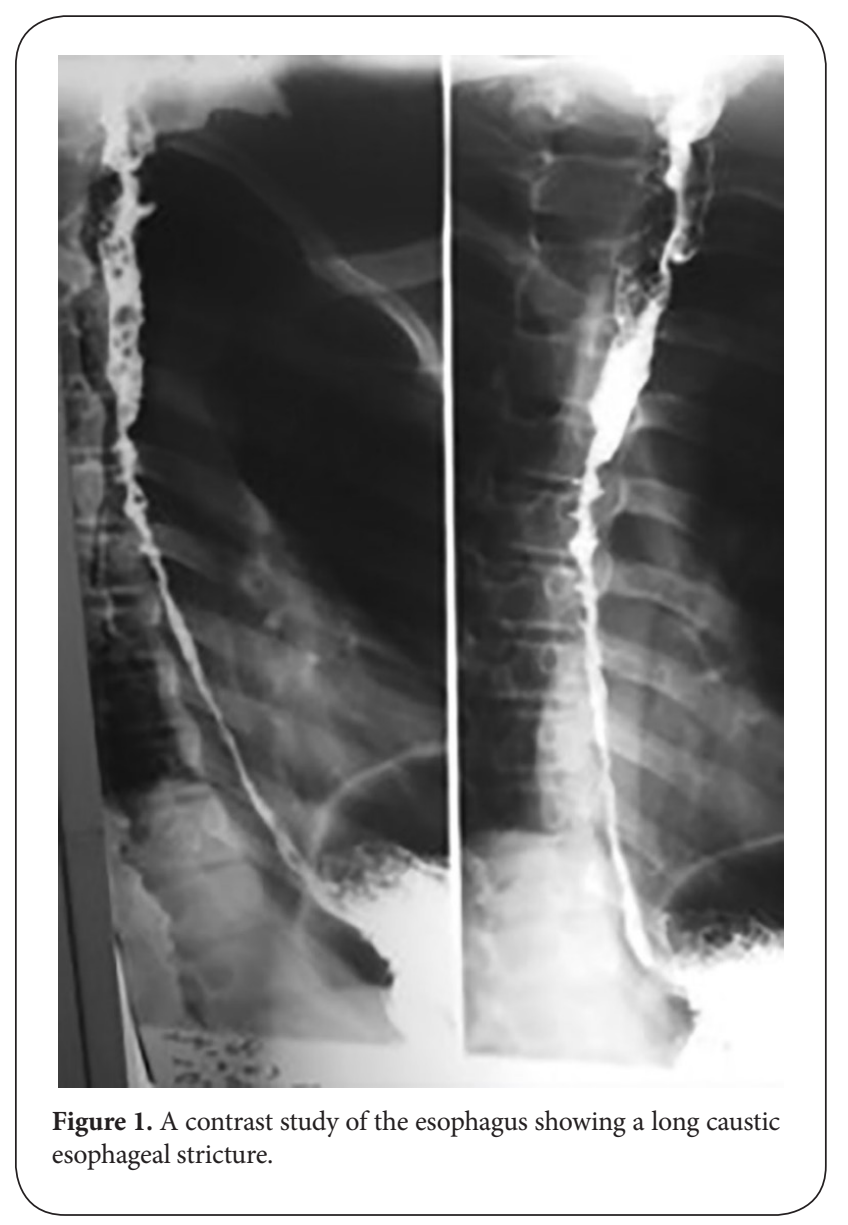

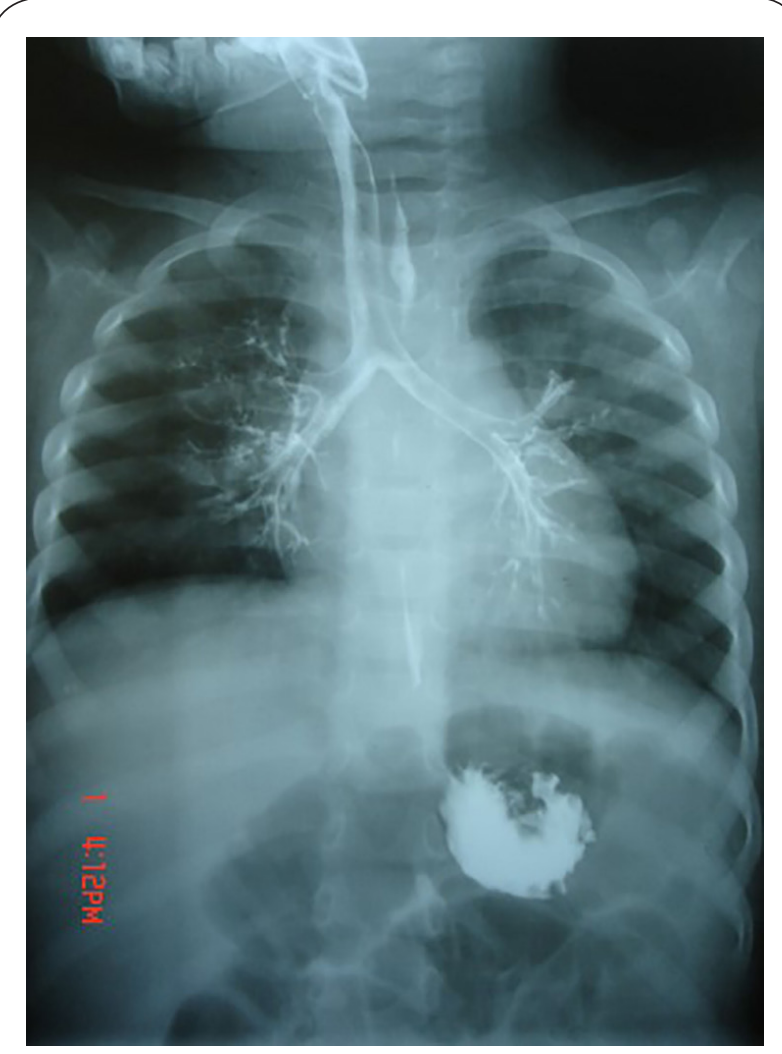

Figure 2. A contrast study of the esophagus showing a tracheaesophageal fistula after caustic ingestion.

the possibility of future stricture formation, the risk of iatrogenic esophageal perforation is high. It is better to be done 6 weeks after the corrosive ingestion to minimize the risk of esophageal perforation. Endoscopic evaluation of the esophagus will confirm the contrast study findings and assess if the stricture if passable or not. It also has the advantage of being therapeutic at the same time (Figure. 3) ${ }^{[5,6]}$.

\section{ENDOSCOPIC MANAGEMENT}

Endoscopic dilatation is considered the cornerstone for management of caustic esophageal stricture.

\section{Endoscopy in the acute phase}

Early endoscopy may be of value as about $30 \%$ of patients with causticingestion may not have esophageal injury and can be discharged promptly. Endoscopy is usually done within 24-48 h after ingestion. However, some centers have recommended endoscopy as soon as possible ${ }^{[7,8]}$. Initial endoscopy after $48 \mathrm{~h}$ of ingestion is not recommended as the injured esophagus may enter the phase of ulceration and granulation, in which the esophagus becomes fragile and easily perforated. Early endoscopy is beneficial to confirm the followings: existence of inju- 
ry, degree of injury, and area of injury which could guide a treatment and predict a prognosis. Early endoscopy is contraindicated in patients with a suspicion of gastrointestinal perforation, necrosis of oral cavity and compromised airway. Gentle handling and avoidance of air over-insufflation is always recommended ${ }^{[9]}$.

\section{Endoscopy in the late phase}

Endoscopy plays an important role in the treatment of caustic esophageal strictures. Caustic stricture is often complex and difficult to dilate ${ }^{[10]}$. Early esophageal dilatation can be done after 3 weeks of caustic ingestion. After 8 weeks, scar tissue is completely formed. Since good nutritional status is strongly related to a successful dilatation of an esophageal stricture, early feeding via gastrostomy should start as soon as patients are clinically stable, especially in those with a significant damage in the esophagus (Figure. 4) ${ }^{[11]}$.

Practically, barium swallow is done at 2-4 weeks after caustic ingestion and dilatation starts at 6 weeks after ingestion. Barium swallow will provide crucial information on the stricture which could determine the safety and success of endoscopic dilatation. Esophageal dilatation can be done using various types of dilators. It can

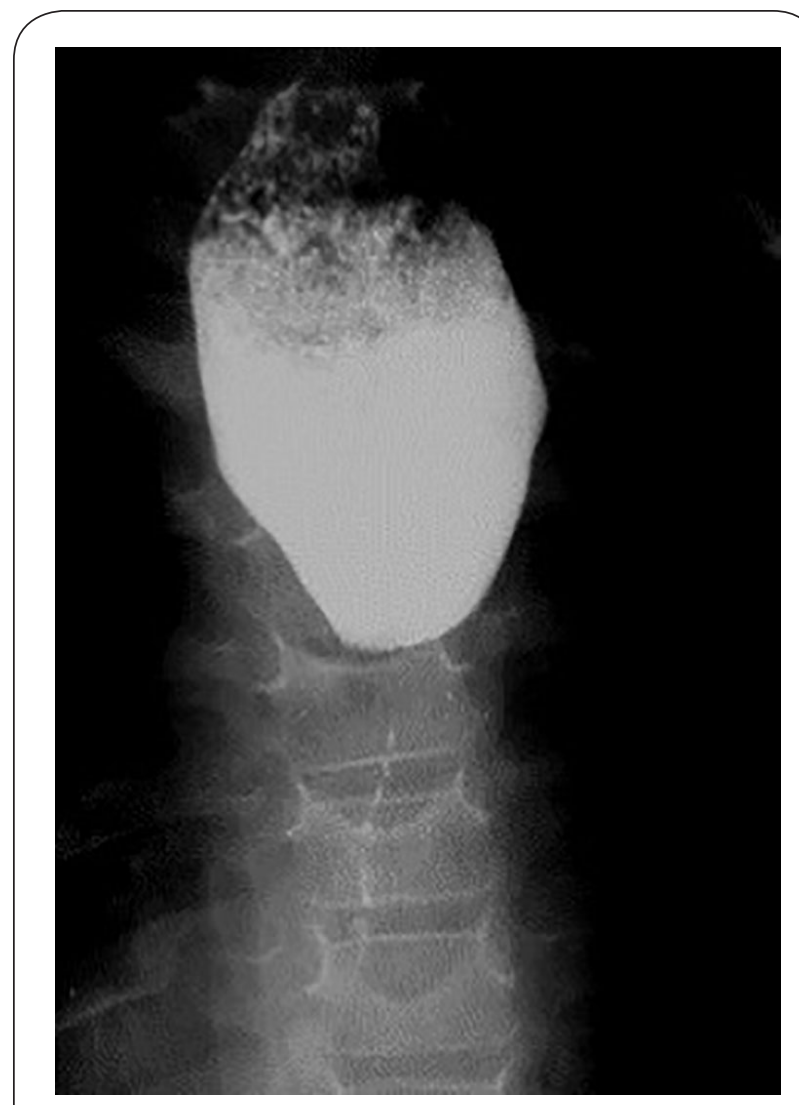

Figure 3. A contrast study of the esophagus showing severe caustic stricture.

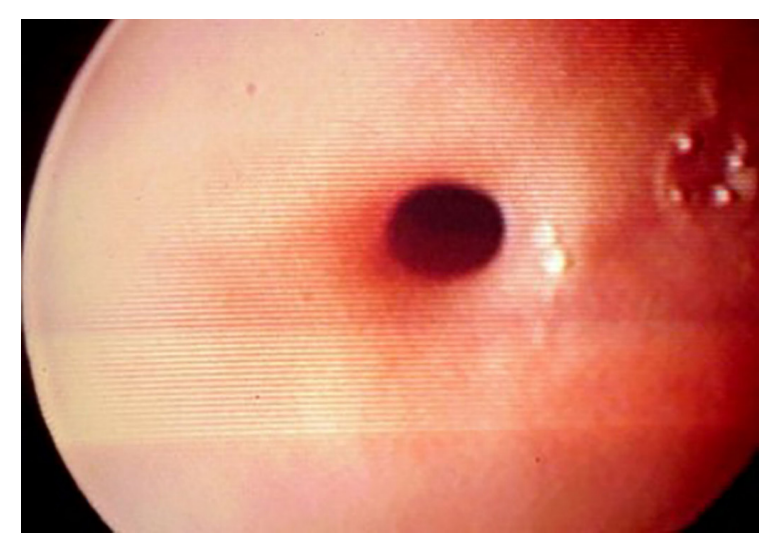

Figure 4. An endoscopic view of a caustic esophageal stricture.

be performed under the combination of endoscopy and fluoroscopy or endoscopy alone ${ }^{[12]}$.

Commonly used esophageal dilatators are:

\section{1-Bougie dilator (Maloney-Hurst dilator):}

This dilator has the advantage of being easy to use but it does not have a channel to insert a guide wire through it. So, it is suitable for short and straight strictures.

\section{2-Wire-guided polyvinyl dilator (Savary-Gilliard di- lator):}

This dilator has a channel through which a guide wire can be passed under fluoroscopy followed by the appropriate dilator. It is suitable for tortuous, angulated and long strictures. Sensation of resistance during dilatation can be felt while using this dilator, thus resulting in protecting against over dilatation and esophageal perforation (Figure. 5).

\section{3-Through-the-scope balloon dilator (CRE balloon dilator):}

This instrument can be passed through the scope. It can reach an area which cannot be accessed by other dilators. However, resistance cannot be felt if over dilatation was done. Dilatation achieved by balloon dilators is through a radial force while other dilators make their action by both radial and longitudinal forces. Although the mechanisms by which dilatation is achieved are different, all dilators have comparable success rates and rate of perforation between $0.1 \%-0.4 \%$ (Figure. 6) ${ }^{[13]}$.

Fluoroscopically guided esophageal balloon dilatation (EBD) offers numerous advantages over endoscopically guided EBD, particularly it provides superior image control and allows visualization of the esophageal stricture (ES) in its entirety (location, severity, length, rigidity, and shape). In the literature, the success rates for fluoroscop- 


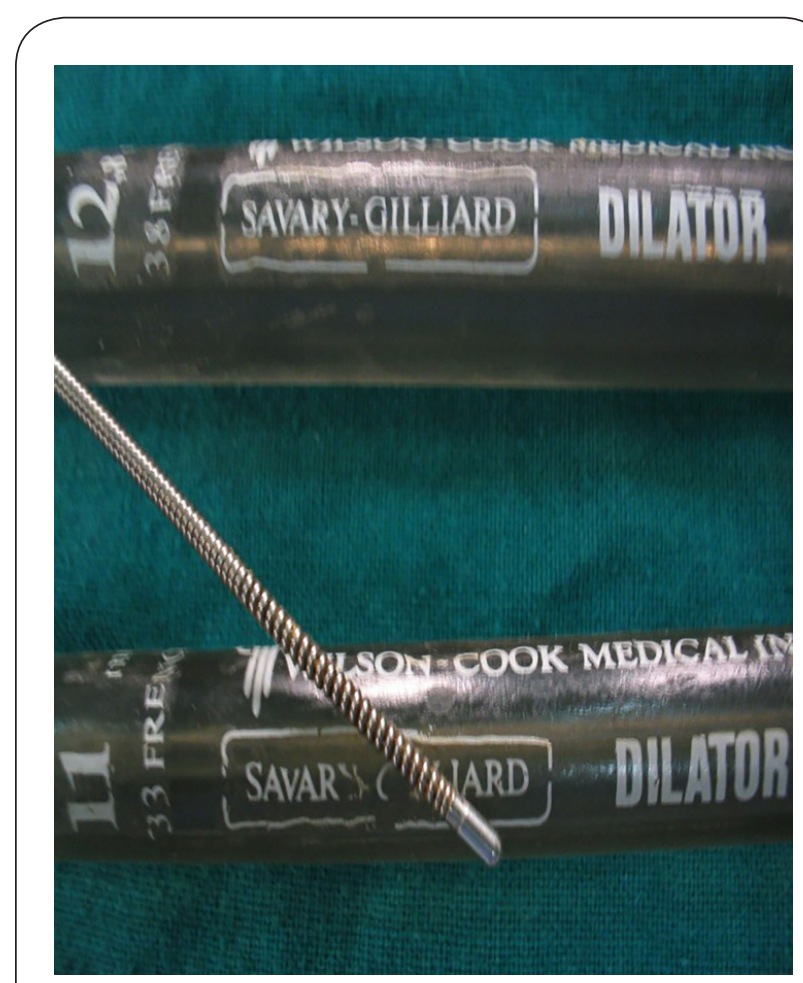

Figure 5. Savary-Gilliard esophageal dilators.

ically guided EBD in children ranged from $64 \%$ to $100 \%$ [14].

EBD can cause external compression of the trachea or obstruction at the endotracheal tube tip. Thus, the surgical team should be aware of obstruction of the airway that may occur during maximal inflation of the balloon. The other disadvantage of EBD is its higher cost compared to that of the other dilators. Although the main complication of EBD is esophageal perforation, the risk is relatively low (0\%-31\%). The mortality rate in the previous decade was close to zero; however, it must be diagnosed earlier ${ }^{[15]}$.

Various modalities with dilatation are advocated to improve the outcome:

\section{Electrocision}

Electro cautery could be applied to a caustic stricture. In this technique, a needle knife is passed through a working channel of the endoscope to make multiple longitudinal incisions until the rim of the stricture disappears. This technique proved to be a useful adjunct in esophageal dilatation.

\section{Intralesional steroid injection}

In this method and before esophageal dilatation, triamcinolone acetonide $(40 \mathrm{mg} / \mathrm{ml})$ is used. $1 \mathrm{~mL}$ is diluted to $2-4 \mathrm{~mL}$ and injected at the stricture site in 4 quadrants. Combination of steroid injection and dilatation can achieve better dilatation, improve dysphagia and reduce dilatation sessions ${ }^{[16]}$.

In our practice, upper endoscopy is usually done under general anesthesia using a flexible one. The size varies according to the age of the patients, but in the majority number $9 \mathrm{~F}$ is suitable to complete the procedure. The scope should be introduced gently under direct vision and mounted by an injection needle connected to a syringe containing $4 \mathrm{ml}$ of diluted 1:1 triamcinolone acetonide. Once the site of stricture is seen, 4 quadrant injection of the stricture is performed avoiding injection at the level of the aortic arch for fear of hemorrhage. The needle is withdrawn, and a metal guidewire is introduced to negotiate the stricture till it can be felt over the epigastrium. Then the scope is withdrawn and a suitable size Savary dilator is passed over the introduced guidewire and pushed with utmost care till felt in the stomach over the epigastrium. Three successive sizes are used in the same session depending on the response of the stricture to dilatation. Failure of passage of the guidewire will end the procedure to be repeated after 2 weeks, and in most cases the guidewire can pass to complete the dilatation procedure. In the presence of a multiple-level stricture, the first one is injected and partial introduction of the dilator over the guidewire will help to dilate the uppermost one followed by repeated sessions to complete the dilatation of the strictures at different levels. With around 30 new cases of caustic esophageal stricture presented to our department per year, studies we conducted found that, success rate of dilatation increased from $32 \%$ with dilatation only to $75 \%$ with steroids injection and $70 \%$ with mitomycin

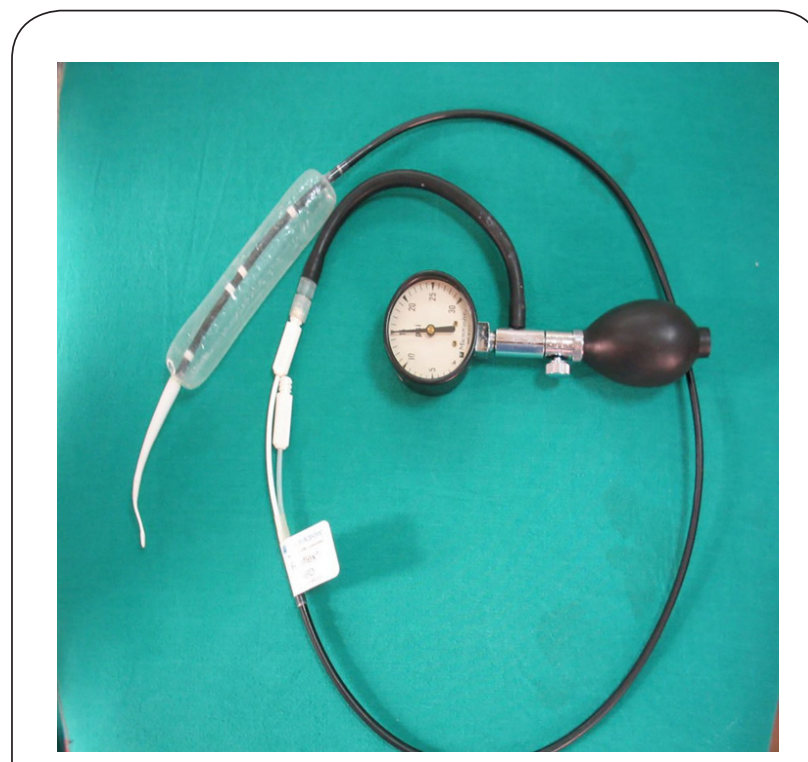

Figure 6. Balloon esophageal dilators. 


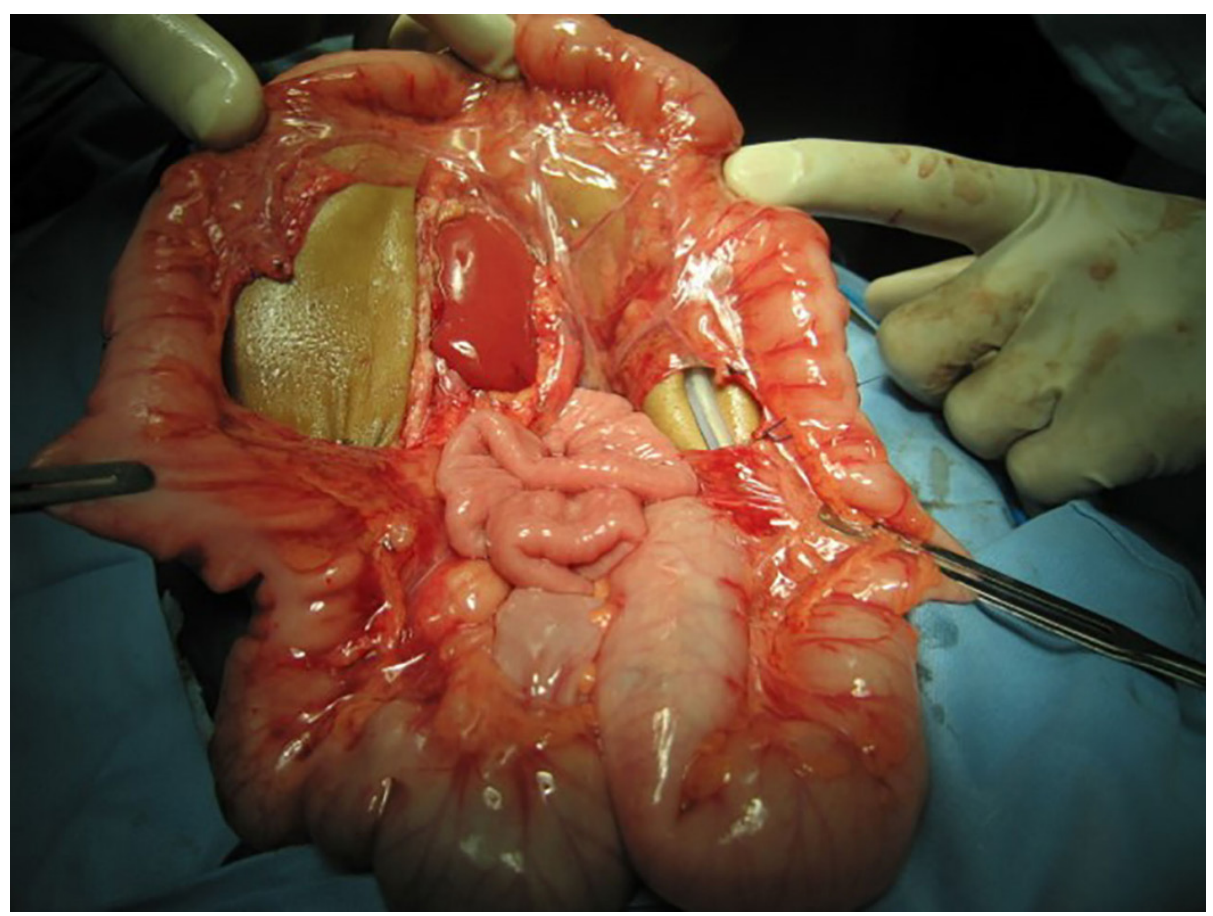

Figure 7. Intraoperative selection of a colonic conduit.

application prior to dilatation, so we don't perform dilatation without either steroids injection or mitomycin application.

\section{Mitomycin-C injection and application}

Injection or application of mitomycin-C into the stricture site was shown to improve dysphagia score and allow easy passage of dilators, because of mitomycin-C inhibited fibroblast proliferation and scar formation without interfering with wound healing ${ }^{[17]}$. A randomized controlled trial done in our department showed a reduction in dilatation sessions if applying mitomycin-C during esophageal dilatation ${ }^{[18]}$.

\section{Esophageal stent}

Caustic esophageal strictures which are resistant to dilatation can be managed with insertion of esophageal stents. Self-expandable plastic stent (SEPS), fully-covered self-expandable metallic stent (FCSEMS) and recently, biodegradable (BD) stent can be used. In practice, SEPS and FCSEMS can be kept in place for 6 weeks but should be removed before 12 weeks. All types of esophageal stents have comparable efficacy, but biodegradable stents have an advantage in avoiding the need for removal. The success rate of stent application in caustic esophageal stricture was 33\% with a migration rate of $40 \%{ }^{[19]}$.

Since its clinical success is about one-third and not long lasting, efficacy is limited and the short-term radial force applied by BD stents is inadequate to provide long term relief in such patients. Esophageal stent is considered as a last resource in the treatment of caustic esophageal injury ${ }^{[20]}$.

The role of endoscopy in the long term follow up:

Since caustic injury of the esophagus has been associated with 1000-fold increased risk of esophageal carcinoma, patients with high grades injury should undergo endoscopic surveillance ${ }^{[21]}$. The incidence of caustic stricure associated esophageal cancer ranged between 0\%-30\% and bypass surgery seems to have no effect on development of cancer. The time between occurrence of caustic injury and malignant transformation of the esophagus was found to be several decades ${ }^{[22]}$. As a result, endoscopic surveillance of the injured esophagus should start at about 15-20 years after occurrence of caustic injury and it should be done every 2 or 3 years ${ }^{[23]}$.

\section{SURGICAL MANAGEMENT}

It should be reserved for strictures which are resistant to multiple sessions of endoscopic dilatation. Due to the high success rates of dilatation with the new modifications in our center, the necessity of esophageal replacement surgery for caustic stricture decreased from around 36 cases to 6 cases per year in the last four years. More than ten years ago, we were performing replacement surgery 
if patient is still having dysphagia after three sessions of dilatation, now this concept has changed too much. Weare exhausting all possible ways to keep the native esophagus and we only consider replacement for cases with persistent non-dilatable strictures or cases who required repeated sessions (more than 20) with no improvement in the spacing for a long period of time (more than 2 years). The ideal esophageal substitute should have good blood supply, grow with the child and do not compromise the cardiac and respiratory functions. The surgical technique should be simple, safe and adaptable to the small children.

The most commonly done operations for esophageal replacement are:

\section{Colon interposition}

It was first described by Kelling and Vulliet in 1911. It is the most commonly done procedure for esophageal replacement. The right (ascending-transverse) or the left (transverse-descending) colon may be used. The conduit can be passed from the abdomen to be anastomosed to the cervical esophagus through a subcutaneous, a retrosternal or a transhiatal route, with the retrosternal being the most commonly used route. The most common postoperative complications are graft necrosis $(0-14 \%)$ and cervical anastomosis leakage (6-28\%) ${ }^{[24-26]}$.

We routinely perform colon interposition as a way for esophageal replacement, as we found it's the best way compared to other replacement surgeries. Through years, we made some modifications in the surgical technique which improved our outcome. We shifted from the transhiatal to the retrosternal route as it has fewer morbidities and mortalities with less operative time, better recovery and less hospital stay. It is better to take the graft with double blood supply and make it iso-peristaltic ${ }^{[27]}$. Antireflux can be made by simple suturing the colon graft to the lesser curvature of the stomach making an angle or by making the colo-gastric anastomosis in the posterior wall of the stomach, these techniques improved the reflux happening after colon interposition ${ }^{[28,29]}$. On the long term follow up, no significant histopathological changes occurred in the colonic conduit (Figure. 7) ${ }^{[30]}$.

\section{Gastric tube}

It was first described by Burrington and Stephens in 1968. A tube is created from the greater curvature of the stomach using a linear cutting gastro-intestinal anastomosis (GIA) stapler after division of the short gastric vessels. It can be also be passed from the abdomen to be anastomosed to the cervical esophagus through a retrosternal or a transhiatal route. The most common postoperative complications are leakage in the neck anastomosis (63\%) and stricture in the tube $(43 \%)^{[31,32]}$.

\section{Gastric transposition}

It was first described by Prof. Lewis Spitz in 1981. The greater and lesser curvatures of the stomach are mobilized. It will be passed from the abdomen to be anastomosed to the cervical esophagus through the transhiatal route. The incidence of postoperative cervical anastomosis leakage is $12-36 \%$ and the incidence of anastomotic stricture is $20-49 \%{ }^{[33,34]}$.

\section{CONCLUSION}

Caustic esophageal strictures could be managed successfully with advanced techniques of endoscopic dilatation.

\section{DECLARATIONS}

\section{Conflicts of interest}

The authors declare that they have no conflict of interest.

Authors' contributions:

Made substantial contributions to conception and design of the study and performed data analysis and interpretation: Sameh Abdelhay, Mohammed Elsherbeny.

Performed data acquisition, as well as provided administrative, technical, and material support: Mohamed Moussa, Mohammed Elsherbeny.

\section{REFERENCES}

1. Arnold, M., \& Numanoglu, A. (2017). Caustic ingestion in children-a review. Seminars in pediatric surgery, 26(2), 95-104.

2. De Lusong, M. A. A., Timbol,A. B.G., \& Tuazon, D. J.S. (2017). Management of esophageal caustic injury. World journal of gastrointestinal pharmacology and therapeutics, 8(2), 90.

3. Köksoy, F. N., \& Gönüllü, D. (2016). The Benign Strictures of the Esophagus. JAREM, 6, 1-14.

4. Levine, M. S., \& Rubesin, S. E. (2005). Diseases of the esophagus: diagnosis with esophagography. Radiology, 237(2), 414-427.

5. Chirica, M., Bonavina, L., Kelly, M.D. (2017). Caustic ingestion. The Lancet, 389 (10083), 2041-2052.

6. Lupa, M., Magne, J., Guarisco, J. L., \& Amedee, R. (2009). Update on the diagnosis and treatment of caustic ingestion. Ochsner Journal, 9(2), 54-59.

7. Weigert, A., \& Black, A. (2005). Caustic ingestion in children. Continuing Education in Anaesthesia, Critical Care \& Pain, 5(1), 5-8. 
8. Kluger, Y., Ishay, O. B., Sartelli, M., Katz, A., Ansaloni, L., Gomez, C. A., ... \& Goran, A. (2015). Caustic ingestion management: world society of emergency surgery preliminary survey of expert opinion. World journal of emergency surgery, 10(1), 48.

9. Poley,J.W.,Steyerberg,E.W.,Kuipers,E.J.,Dees,J.,Hartmans, R., Tilanus, H.W., \& Siersema, P. D. (2004). Ingestion of acid and alkaline agents: outcome and prognostic value of early upper endoscopy. Gastrointestinal endoscopy, 60(3), 372-377.

10. Rodrigues-Pinto, E., Pereira, P., Ribeiro, A., Lopes, S., Moutinho-Ribeiro, P., Silva, M., ... \& Macedo, G. (2016). Risk factors associated with refractoriness to esophageal dilatation for benign dysphagia. European journal of gastroenterology \& hepatology, 28(6), 684-688.

11. Contini, S., Swarray-Deen, A., \& Scarpignato, C. (2009). Oesophageal corrosive injuries in children: a forgotten social and health challenge in developing countries. Bulletin of the World Health Organization, 87, 950-954.

12. Siddeshi, E. R., Krishna, M. V., Jaiswal, D., \& Krishna, M. M. (2015). Safety and outcome using endoscopic dilation for benign esophageal stricture without fluoroscopy. Journal of Digestive Endoscopy, 6(02), 055-058.

13. Scolapio, J. S., Pasha, T. M., Gostout, C. J., Mahoney, D. W., Zinsmeister, A. R., Ott, B. J., \& Lindor, K. D. (1999). A randomized prospective study comparing rigid to balloon dilators for benign esophageal strictures and rings. Gastrointestinal endoscopy, 50(1), 13-17.

14. Temiz, A., Oguzkurt, P., Ezer, S. S., Ince, E., \& Hicsonmez, A. (2010). Long-term management of corrosive esophageal stricture with balloon dilation in children. Surgical endoscopy, 24(9), 2287-2292.

15. Contini, S., Scarpignato, C., Rossi, A., \& Strada, G. (2011). Features and management of esophageal corrosivelesions in children in Sierra Leone: lessons learned from 175 consecutive patients. Journal of pediatric surgery, 46(9), 1739-1745.

16. Nijhawan, S., Udawat, H. P., \& Nagar, P. (2016). Aggressive bougie dilatation and intralesional steroids is effective in refractory benign esophageal strictures secondary to corrosive ingestion. Diseases of the Esophagus, 29(8), 1027-1031.

17. Divarci, E., Kilic, O., Dokumcu, Z., Ozcan, C., \& Erdener, A. (2017). Topical Mitomycin C Application Is Effective Even in Esophageal Strictures Resistant to Dilatation Therapy in Children. Surgical laparoscopy, endoscopy \& percutaneous techniques, 27(5), e96-e100.

18. El-Asmar, K. M., Hassan, M. A., Abdelkader, H. M., \& Hamza, A. F. (2013). Topical mitomycin C application is effective in management of localized caustic esophageal stricture: a double-blinded, randomized, placebo-controlled trial. Journal of pediatric surgery, 48(7), 1621-1627.

19. Suzuki, T., Siddiqui, A., Taylor, L. J., Cox, K., Hasan, R. A., Laique, S. N., ... \& Adler, D. G. (2016). Clinical outcomes, efficacy, and adverse events in patients undergoing esophageal stent placementfor benign indications. Journal of clinical gastroenterology, 50(5), 373-378.

20. Repici, A., Small, A. J., Mendelson, A., Jovani, M., Correale, L., Hassan, C., ... \& Kochman, M. L. (2016). Natural history and management of refractory benign esophageal strictures. Gastrointestinal endoscopy, 84(2), 222-228.

21. Contini, S., \& Scarpignato, C. (2013). Caustic injury of the upper gastrointestinal tract: a comprehensive review. World journal of gastroenterology: WJG, 19(25), 3918.

22. Ntanasis-Stathopoulos, I., Triantafyllou, S., Xiromeritou, V., Bliouras, N., Loizou, C., \& Theodorou, D. (2016). Esophageal remnant cancer 35 years after acidic caustic injury: A case report. International journal of surgery case reports, 25, 215-217.

23. Evans, J. A., Early, D. S., Fukami, N., Ben-Menachem, T., Chandrasekhara, V., Chathadi, K. V., ... \& Hwang, J. H. (2012). The role of endoscopy in Barrett's esophagus and other premalignant conditions of the esophagus. Gastrointestinal endoscopy, 76(6), 10871094.

24. Boukerrouche, A. (2014). Isoperistaltic left colic graft interposition via a retrosternal approach for esophageal reconstruction in patients with a caustic stricture: mortality, morbidity, and functional results. Surgery today, 44(5), 827-833.

25. Boukerrouche, A. (2013). Left colonic graft in esophageal reconstruction for caustic stricture: mortality and morbidity. Diseases of the Esophagus, 26(8), 788-793.

26. Tannuri, A. C. A., \& Tannuri, U. (2017). Total esophageal substitutionforcombinedhypopharyngealand esophageal strictures after corrosive injury in children. Journal of pediatric surgery, 52(11), 1742-1746.

27. Hamza, A. F., Abdelhay, S., Sherif, H., Hasan, T., Soliman, H., Kabesh, A., ... \& Bahnassy, A. F. (2003). Caustic esophageal strictures in children: 30 years' experience. Journal of pediatric surgery, 38(6), 828-833.

28. Abdel-Latif, M., El-Shafei, E.A.,El-Asmar, K. M., \&Abdel-Hay, S. (2016). Simple antireflux technique for the cologastric anastomosis: complementary step in retrosternal colon interposition procedure. Diseases of the Esophagus, 29(8), 1002-1006.

29. AbouZeid, A. A., Zaki, A. M., \& Safoury, H. S. (2016). Posterior cologastric anastomosis: an effective antireflux 
mechanism in colonic replacement of the esophagus. The Annals of thoracic surgery, 101(1), 266-273.

30. Elshafei, H., Elshafei, E., ElDebeiky, M., Hegazy, N., Zaki, A., \& Hay, S. A. (2012). Colonic conduit for esophageal replacement: long-term endoscopic and histopathologic changes in colonic mucosa. Journal of pediatric surgery, 47(9), 1658-1661.

31. Elfiky, M. M., El Tagy, G., Mohamed, W., Azim, O. A., \& Elfiky, M. A. (2017). Gastric tube esophagoplasty for pediatric esophageal replacement. Journal of pediatric surgery, 52(4), 657-662.

32. Sharma, S., \& Gupta, D. K. (2017). Surgical techniques for esophageal replacement in children. Pediatric surgery international, 33(5), 527-550.

33. Angotti, R., Molinaro, F., Noviello, C., Cobellis, G., Martino, A., Del Rossi, C., ... \& Messina, M. (2017). Gastric transposition as a valid surgical option for esophageal replacement in pediatric patients: experience from three Italian medical centers. Gastroenterology report, 5(1), 47-51.

34. Foster, J. D., Hall, N. J., Keys, S. C., \& Burge, D. M. (2018). Esophageal replacement by gastric transposition: A single surgeon's experience from a tertiary pediatric surgical center. Journal of pediatric surgery, 53(11), 2331-2335. 